\title{
Nuclear Quadrupole Coupling Effects in the Rotational Spectrum of 4-Cyanopyridine
}

\author{
Nils Heineking and Helmut Dreizler \\ Abteilung Chemische Physik im Institut für Physikalische Chemie \\ der Christian-Albrechts-Universität zu Kiel
}

Z. Naturforsch. 42 a, 83-86 (1987); received August 23, 1986

\begin{abstract}
The quadrupole coupling of the two nitrogen nuclei was investigated by microwave Fourier transform spectroscopy. The results contribute to a comparison of substituent effects in different pyridine derivatives.
\end{abstract}

We investigated the nitrogen hyperfine structure (hfs) in the rotational spectrum of 4-cyanopyridine or isonicotinonitrile, $\mathrm{C}_{6} \mathrm{H}_{4} \mathrm{~N}_{2}$, by use of microwave Fourier transform (MWFT) spectroscopy [1]. This paper is the third in a series, in which the effects of different substituents on the electronic environment of the pyridine ring nitrogen nucleus are compared.

The pure rotational spectrum of 4-cyanopyridine has been analysed by Ford [2], who reported the rotational constants and the dipole moment. $\mathrm{He}$ could not resolve the complex hyperfine structure.

Using our MWFT-spectrometers in the range from 5.3 to $26 \mathrm{GHz}$ [3-6] we recorded some thirty rotational transitions at pressures of $0.4-1.5 \mathrm{mT}$ Torr $(0.05-0.2 \mathrm{~Pa})$ and temperatures between $+25^{\circ} \mathrm{C}$ and $-20^{\circ} \mathrm{C}$. The hyperfine structure could not always be completely resolved, but the information gained proved sufficient to distinguish the two nitrogen nuclei and allowed an interpretation of the quadrupole coupling.

The white, crystalline substance $\left(\mathrm{mp} .: 78^{\circ} \mathrm{C}\right)$ was purchased from FLUKA, Neu-Ulm, and sublimated for purification.

A selection of the measurements is given in Table 1 . The complete list is available under TNA 6 at the Universitätsbibliothek Kiel*. The multiplets were simulated by line shape analysis [7] to account for interference of neighbouring components. A sample of the recordings is given in Fig. 1, showing the K-doublet transitions $J_{K_{-} K_{+}}=8_{71}-7_{70}$ and

* Westring 400, D-2300 Kiel.

Reprint requests to Prof. Dr. H. Dreizler, Institut für Physikalische Chemie, Universität Kiel, Olshausenstr. 40, D-2300 Kiel.
$8_{72}-7_{71}$ split into nine hyperfine components by the coupling effects of the two nitrogen nuclei.

The nuclear quadrupole coupling energies being small compared with the rotational energy, a first order hfs analysis [8] is sufficient. Because the coupling energies of the ring and cyano nitrogen nuclei are of equal magnitude we predetermined the hfs by use of the three possible coupling schemes $\left(I_{1}=I(\right.$ ring N $), I_{2}=I($ cyano $\left.\mathrm{N})\right)$

$$
\begin{array}{ll}
F_{1}=J+I_{1} ; & F_{1}+I_{2}=F ; \\
F_{1}=J+I_{2} ; & F_{1}+I_{1}=F ; \\
I=I_{1}+I_{2} ; & J+I=F .
\end{array}
$$

We used the coupling constants of pyridine $\left(\chi_{a a}=\right.$ $-4.908(3) \mathrm{MHz}, \chi_{b b}=1.434$ (3) $\mathrm{MHz}, \chi_{c c}=3.474$ (3) $\mathrm{MHz}, \quad \eta=\left|\left(\chi_{b b}-\chi_{c c}\right) / \chi_{a a}\right|=0.416(2)$ [9]) for the

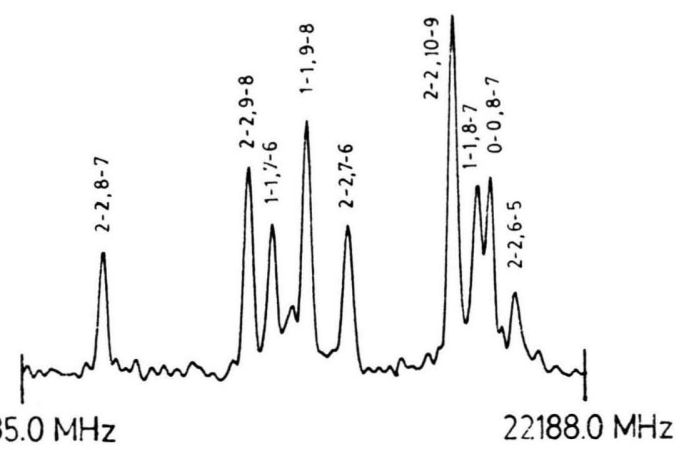

Fig. 1. Rotational transitions $J_{K_{-} K_{+}}=8_{71}-7_{70}$ and $8_{72}-7_{71}$ of 4-cyanopyridine, showing nuclear quadrupole hyperfine structure ( $I$ and $F$ quantum numbers given). A range of $3 \mathrm{MHz}$ out of a $25 \mathrm{MHz}$ recording, polarizing frequency $22187 \mathrm{MHz}$, cell temperature $8^{\circ} \mathrm{C}$, gas pressure $0.4 \mathrm{mTorr}$ $=0.05 \mathrm{~Pa}, 8 \cdot 10^{6}$ averaging cycles, sampling interval $20 \mathrm{~ns}$. 1024 data points were supplemented by 3072 zeros prior to Fourier transformation. 
Table 1. Selection of measured rotational transitions of 4-cyanopyridine. $v$ observed frequencies, $\Delta v$ hyperfine splittings referred to strongest multiplet components. $v_{0}$ unsplit transition frequencies, $\Delta(\Delta v)$ deviations of the splittings from calculated values, $\Delta v_{0}$ deviations from rigid rotor spectrum. The latter two were calculated with the quadrupole and rotational constants from Table 2.

\begin{tabular}{|c|c|c|c|c|c|c|c|c|c|c|c|c|}
\hline$J^{\prime}$ & $K$ & $K^{\prime}$ & $-J^{\prime \prime}$ & $K_{-}^{\prime \prime}$ & $K_{+}^{\prime \prime}$ & $I^{\prime}-I^{\prime \prime}$ & $F^{\prime}-F^{\prime \prime}$ & $\begin{array}{l}v \\
{[\mathrm{MHz}]}\end{array}$ & $\begin{array}{l}\Delta v \\
{[\mathrm{MHz}]}\end{array}$ & $\begin{array}{l}v_{0} \\
{[\mathrm{MHz}]}\end{array}$ & $\begin{array}{l}\Delta(\Delta v) \\
{[\mathrm{kHz}]}\end{array}$ & $\begin{array}{l}\Delta v_{0} \\
{[\mathrm{kHz}]}\end{array}$ \\
\hline 2 & 0 & 2 & -1 & 0 & 1 & $\begin{array}{l}1-1, \\
1-1 \\
2-2 \\
2-2\end{array}$ & $\begin{array}{l}3-2 \\
2-1 \\
4-3 \\
3-2\end{array}$ & $\begin{array}{l}5518.130 \\
5518.259 \\
5518.424 \\
5518.518\end{array}$ & $\begin{array}{l}-0.294 \\
-0.165 \\
+0.094\end{array}$ & $5518.222 *$ & $\begin{array}{r}0 \\
+34 \\
+12\end{array}$ & -11 \\
\hline 2 & 1 & 1 & -1 & 1 & 0 & $\begin{array}{l}1-1 \\
2-2\end{array}$ & $\begin{array}{l}3-2 \\
4-3\end{array}$ & $\begin{array}{l}5849.378 \\
5850.084\end{array}$ & -0.706 & $5849.538 *$ & +11 & +12 \\
\hline 2 & 1 & 2 & -1 & 1 & 1 & $\begin{array}{l}1-1 \\
2-2\end{array}$ & $\begin{array}{l}3-2 \\
4-3\end{array}$ & $\begin{array}{l}5218.999 \\
5219.773\end{array}$ & -0.774 & $5219.190 *$ & -22 & +10 \\
\hline 3 & 0 & 3 & -2 & 0 & 2 & $\begin{array}{l}2-2, \\
2-2, \\
0-0 \\
1-1, \\
1-1, \\
2-2, \\
2-2 \\
1-1,\end{array}$ & 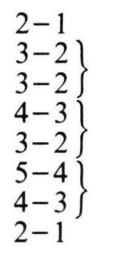 & $\begin{array}{l}8236.660 \\
8237.141 \\
8237.271 \\
8237.453 \\
8237.552\end{array}$ & $\begin{array}{l}-0.793 \\
-0.312 \\
-0.182 \\
+0.099\end{array}$ & $8237.327 *$ & $\begin{array}{l}+17 \\
-4 \\
-30 \\
+15\end{array}$ & -2 \\
\hline 3 & 1 & 2 & -2 & 1 & 1 & $\begin{array}{l}2-2, \\
2-2, \\
2-2, \\
1-1, \\
1-1, \\
0-0 \\
2-2, \\
1-1\end{array}$ & $\left.\begin{array}{l}3-2 \\
2-1 \\
4-3 \\
2-1 \\
4-3 \\
3-2 \\
5-4 \\
3-2\end{array}\right\}$ & $\begin{array}{l}8763.349 \\
8763.735 \\
8763.820 \\
8764.181 \\
8764.262\end{array}$ & $\begin{array}{l}-0.832 \\
-0.446 \\
-0.361 \\
+0.081\end{array}$ & $8763.946 *$ & $\begin{array}{l}+5 \\
-12 \\
+8 \\
+2\end{array}$ & +3 \\
\hline 3 & 1 & 3 & -2 & 1 & 2 & $\begin{array}{l}2-2, \\
2-2, \\
2-2, \\
1-1 \\
1-1 \\
2-2 \\
0-0 \\
2-2 \\
1-1\end{array}$ & $\left.\begin{array}{l}3-2 \\
2-1 \\
4-3 \\
2-1 \\
4-3 \\
1-0 \\
3-2 \\
5-4 \\
3-2\end{array}\right\}$ & $\begin{array}{c}7818.306 \\
7818.700 \\
7818.833 \\
7819.083 \\
7819.194\end{array}$ & $\begin{array}{l}-0.888 \\
-0.494 \\
-0.361 \\
-0.111\end{array}$ & $7818.917 *$ & $\begin{array}{l}+16 \\
+14 \\
+27 \\
-28\end{array}$ & +5 \\
\hline 3 & 2 & 1 & -2 & 2 & 0 & $\begin{array}{l}2-2 \\
1-2 \\
2-2 \\
1-1 \\
1-1 \\
2-1 \\
2-2 \\
1-1 \\
2-2 \\
0-1 \\
2-2 \\
1-0 \\
0-0\end{array}$ & $\left.\begin{array}{l}3-2 \\
4-3 \\
4-3 \\
2-1 \\
4-3 \\
4-3 \\
5-4 \\
3-2 \\
2-1 \\
3-2 \\
1-1 \\
3-2 \\
3-2\end{array}\right\}$ & $\begin{array}{l}8363.716 \\
8364.321 \\
8364.403 \\
8364.595 \\
8365.374 \\
8365.435 \\
8366.385 \\
8366.853\end{array}$ & $\begin{array}{l}-2.669 \\
-2.064 \\
-1.982 \\
-1.790 \\
-1.011 \\
-0.950 \\
\\
+0.468\end{array}$ & 8365.724 * & $\begin{array}{l}-7 \\
-29 \\
-19 \\
-1 \\
-8 \\
-19 \\
\\
-16 \\
-14\end{array}$ & -3 \\
\hline 3 & 2 & 2 & -2 & 2 & 1 & $\begin{array}{l}2-2, \\
2-2, \\
1-1, \\
1-1, \\
2-2, \\
1-1, \\
2-2, \\
0-0,\end{array}$ & $\left.\begin{array}{l}3-2 \\
4-3 \\
2-1 \\
4-3 \\
5-4 \\
3-2 \\
2-1 \\
3-2\end{array}\right\}$ & $\begin{array}{l}8299.480 \\
8300.169 \\
8300.311 \\
8301.189 \\
8302.184 \\
8302.671 \\
8303.054\end{array}$ & $\begin{array}{l}-2.704 \\
-2.015 \\
-1.873 \\
-0.995 \\
+0.487 \\
+0.870\end{array}$ & $8301.520 *$ & $\begin{array}{l}-14 \\
-10 \\
-36 \\
-11 \\
-9 \\
-5\end{array}$ & -10 \\
\hline
\end{tabular}


ring nitrogen and those of benzonitrile $\left(\chi_{a a}=\right.$ $-4.187(70) \mathrm{MHz}, \quad \chi_{b b}=2.301(53) \mathrm{MHz}, \quad \chi_{c c}=$ $1.886(53) \mathrm{MHz}, \eta=0.099(30)$ [10]) for the cyano nitrogen. All calculations gave the same result. In Table 1 we give the quantum numbers of the third coupling scheme.

For each multiplet, the hypothetical unsplit transition frequency was calculated by adding the hfs correction to the frequency of the strongest component. The low-J-transitions (up to $\mathrm{J}=3$ ) were used for a rigid rotor analysis to refine the rotational constants. This refinement did not influence the hfs analysis. We used our programs Q2SIM [11], Q2FIT [12], and QUAD2 [13] for the hfs- and DH9 [14] for the rotational analysis. The rotational and nuclear quadrupole coupling constants are given in Table 2 . The assignment to the two nitrogen nuclei was based on a comparison with the coupling constants of pyridine and benzonitrile.

An interpretation of the ring nitrogen coupling will be given in a forthcoming paper. The discussion of the cyano nitrogen coupling is comparable to that of the chlorine coupling in aryl chlorides [15]. Unfortunately one has to make more assumptions:

The cyano nitrogen is $\sigma$ bonded by a partially s-hybridized $p_{z}$ orbital, and $\pi$ bonded by two $p_{x}$ and $p_{y}$ orbitals, respectively. The counterhybridized

Table 2. Rotational and quadrupole coupling constants of 4-cyanopyridine. $\sigma$ standard deviation of the fit. $|(B, C)|$ maximum correlation coefficient; derived parameters below the line, $\eta=\left|\left(\chi_{b b}-\chi_{c c}\right) / \chi_{a a}\right|$. Quoted errors are single standard errors.

\begin{tabular}{|c|c|c|}
\hline $\begin{array}{l}A \\
B \\
C\end{array}$ & $\begin{array}{l}=6001.2(5) \\
=1541.175(2) \\
=1226.002(2)\end{array}$ & $\begin{array}{l}\mathrm{MHz} \\
\mathrm{MHz} \\
\mathrm{MHz}\end{array}$ \\
\hline$|(B, C)|$ & $\begin{array}{l}=\quad 10 \\
=\quad 0.792\end{array}$ & $\mathrm{kHz}$ \\
\hline $\begin{array}{l}\chi_{a a}(\operatorname{ring} \mathrm{N}) \\
\chi_{b b}(\text { ring N)}) \\
\chi_{a a}(\text { cyano N) } \\
\chi_{b b}(\text { cyano N) }\end{array}$ & $\begin{array}{lr}= & -5.02(4) \\
= & 1.41(11) \\
= & -4.28(4) \\
= & 2.37(10)\end{array}$ & $\begin{array}{l}\mathrm{MHz} \\
\mathrm{MHz} \\
\mathrm{MHz} \\
\mathrm{MHz}\end{array}$ \\
\hline $\mid\left(\chi_{a a}(\operatorname{ring} \mathrm{N}), \chi_{a a}(\right.$ cyano $\left.\mathrm{N})\right) \mid$ & $\begin{array}{ll}= & 21 \\
= & 0.891\end{array}$ & $\mathrm{kHz}$ \\
\hline $\begin{array}{l}\chi_{c c}(\text { ring } \mathrm{N}) \\
\eta(\text { ring } \mathrm{N}) \\
\chi_{c c}(\text { cyano } \mathrm{N}) \\
\eta(\text { cyano } \mathrm{N})\end{array}$ & $\begin{array}{l}3.61(12) \\
0.438(45) \\
1.91(11) \\
0.107(48)\end{array}$ & $\mathrm{MHz}$ \\
\hline
\end{tabular}

orbital contains the lone pair electrons. Because the polarisations $i_{\sigma}, i_{\pi_{x}}$, and $i_{\pi_{\nu}}$ of the $\sigma, \pi_{x}$, and $\pi_{y}$ bonds and the hybridization parameter $a_{\mathrm{s}}^{2}$ are unknowns there are four parameters and only two experimental data. We assume that the $\pi_{x}$ bond in the molecular plane is entirely homeopolar, i.e. $i_{\pi_{x}}=0$, and that the ionicity of the $\sigma$ bond is $25 \%$. This follows from the electronegativities of nitrogen and carbon with an empirical relation [16]. The occupation numbers of the nitrogen $p$ orbitals are then given by

$n_{x}=1, n_{y}=1+i_{\pi_{y}}, \quad n_{z}=\left(1+i_{\sigma}\right)\left(1-a_{\mathrm{s}}^{2}\right)+2 a_{\mathrm{s}}^{2}$.

With the charge correction [17] applied, the following expressions result [18]:

$$
\begin{aligned}
& \chi_{z z}=\chi_{a a}=\frac{a_{\mathrm{s}}^{2}\left(1-i_{\sigma}\right)+i_{\sigma}-\frac{1}{2} i_{\pi_{v}}}{1+\varepsilon \cdot i_{\sigma}+\varepsilon \cdot i_{\pi_{\nu}}} e Q q_{210}, \\
& \chi_{x x}=\chi_{b b}=\frac{-\frac{1}{2} a_{\mathrm{s}}^{2}\left(1-i_{\sigma}\right)-\frac{1}{2} i_{\sigma}-\frac{1}{2} i_{\pi_{\nu}}}{1+\varepsilon \cdot i_{\sigma}+\varepsilon \cdot i_{\pi_{\nu}}} e Q q_{210},
\end{aligned}
$$

where $\chi_{g g}$ are the nuclear quadrupole coupling constants, $g=x, z, a, b ; e Q q_{210}$ is the quadrupole coupling of an electron in $\mathrm{nlm}=210$ state; $\varepsilon=$ the shielding constant.

Equations (2) yield

$$
i_{\pi_{\nu}}=\frac{1+\varepsilon \cdot i_{\sigma}}{\frac{-\frac{3}{2} e Q q_{210}}{\chi_{a a}+2 \chi_{b b}}-\varepsilon}
$$

and with $\varepsilon \cdot i_{\pi_{\nu}} \ll 1+\varepsilon \cdot i_{\sigma}$

$$
a_{\mathrm{s}}^{2}=\frac{\left(\chi_{a a}-\chi_{b b}\right) \cdot\left(1+\varepsilon \cdot i_{\sigma}\right)}{\frac{3}{2} e Q q_{210} \cdot\left(1-i_{\sigma}\right)}-\frac{i_{\sigma}}{\left(1-i_{\sigma}\right)} .
$$

With the experimental results for the coupling constants (see Table 2) and the values $\varepsilon=0.3$ [17] and $e Q q_{210}=-9.38 \mathrm{MHz}$ [19], we get

$$
i_{\pi_{v}}=3.5 \% \text { and } a_{\mathrm{s}}^{2}=34 \% .
$$

Because these values are rather sensitive to the assumptions no standard errors are given.

It should be noted that the hybridization parameter $a_{\mathrm{s}}^{2}$ cannot (according to (3)) reach 50\% ("sp"hybridization) unless the $\sigma$ bond polarity is nearly zero, what would leave unexplained the high dipole moment of approximately $4 \mathrm{D}$ of the cyano group. 


\section{Acknowledgement}

We would like to thank the members of our group for help and discussions, the Deutsche For-

11] H. Dreizler, J. Mol. Phys. 59, 1 (1986).

[2] R. G. Ford, J. Mol. Spectrosc. 58, 178 (1975).

[3] G. Bestmann, H. Dreizler, E. Fliege, and W. Stahl, J. Mol. Struct. 97, 215 (1983).

[4] G. Bestmann and H. Dreizler, Z. Naturforsch. 37 a, 58 (1982).

[5] G. Bestmann, H. Dreizler, H. Mäder, and U. Andresen, Z. Naturforsch. 35a, 392 (1980).

[6] W. Stahl, G. Bestmann, H. Dreizler, U. Andresen, and R. Schwarz, Rev. Sci. Instrum. 56, 1759 (1985)

[7] E. Fliege and H. Dreizler, Z. Naturforsch. 39a, 630 (1984).

[8] W. Gordy and R. L. Cook, Microwave Molecular Spectra, John Wiley, New York 1984, Chapter IX, 5; XV 3.

[9] N. Heineking, H. Dreizler, and R. Schwarz, Z. Naturforsch. $41 \mathrm{a}, 1210$ (1986). schungsgemeinschaft and Fonds der Chemie for funds. The calculations were made at the computer centre of the University of Kiel.

[10] E. Fliege, G. Bestmann, R. Schwarz, and H. Dreizler, Z. Naturforsch. 36a, 1124 (1981); The error calculations have been revised.

[11] Authors: H. Günter, Tübingen, J. Reinstätler, Gießen.

[12] D. Hübner and M. Stolze, Kiel.

[13] G. L. Blackman and B. Kleibömer, Monash University, Melbourne.

[14] G. Herberich, Aachen.

[15] N. Heineking and H. Dreizler, Z. Naturforsch. (1986), to be published.

[16] Loc. cit. [8], Eq. (14.93) and App. G.

[17] J. C. H. Townes and A. L. Shawlow, Microwave Spectroscopy, McGraw Hill, New York 1955; Chapt. 9.4, Table 9.5 .

[18] Loc. cit. [8], analogous to (14.89).

[19] W. Kasten, H. Dreizler, and R. L. Kuczkowski, Z. Naturforsch. 40 a, 1262 (1985). 